OPEN ACCESS

Edited by:

Pedro A. Reche,

Complutense University of

Madrid, Spain

Reviewed by:

Ji Wang,

Sun Yat-sen University, China

Wayne Robert Thomas,

University of Western

Australia, Australia

*Correspondence:

Lei Jin

lei.jin@medicine.ufl.edu

tThese authors have contributed equally to this work

Specialty section

This article was submitted to Vaccines and Molecular Therapeutics,

a section of the journal

Frontiers in Immunology

Received: 28 April 2020

Accepted: 23 June 2020

Published: 07 August 2020

Citation:

Gogoi H, Mansouri S, Katikaneni DS and $\operatorname{Jin} L$ (2020) New

MoDC-Targeting TNF Fusion Proteins Enhance Cyclic Di-GMP Vaccine

Adjuvanticity in Middle-Aged and Aged Mice. Front. Immunol. 11:1674.

doi: 10.3389/fimmu.2020.01674

\section{New MoDC-Targeting TNF Fusion Proteins Enhance Cyclic Di-GMP Vaccine Adjuvanticity in Middle-Aged and Aged Mice}

\author{
Himanshu Gogoi ${ }^{\dagger}$, Samira Mansouri ${ }^{\dagger}$, Divya S. Katikaneni and Lei Jin* \\ Division of Pulmonary, Critical Care and Sleep Medicine, Department of Medicine, University of Florida, Gainesville, FL, \\ United States
}

Cyclic dinucleotides (CDNs) are promising vaccine adjuvants inducing balanced, potent humoral, and cellular immune responses. How aging influences CDN efficacy is unclear. We examined the vaccine efficacy of $3^{\prime}, 5^{\prime}$-cyclic diguanylic acid (cyclic di-GMP, CDG), the founding member of CDNs, in 1-year-old (middle-aged) and 2-year-old (aged) C57BL/6J mice. We found that 1- and 2-year-old C57BL/6J mice are defective in CDG-induced memory $T$ helper (Th) 1 and Th17 responses and high-affinity serum immunoglobulin (lg)G, mucosal IgA production. Next, we generated two novel tumor necrosis factor (TNF) fusion proteins that target soluble TNF (solTNF) and transmembrane TNF (tmTNF) to monocyte-derived dendritic cells (moDCs) to enhance CDG vaccine efficacy in 1- and 2-year-old mice. The moDC-targeting TNF fusion proteins restored CDG-induced memory Th1, Th17, and high-affinity lgG, IgA responses in the 1- and 2-year-old mice. Together, the data suggested that aging negatively impacts CDG vaccine adjuvanticity. MoDC-targeting TNF fusion proteins enhanced CDG adjuvanticity in the aging mice.

\footnotetext{
Keywords: $3^{\prime}, 5^{\prime}$-cyclic diguanylic acid (cyclic di-GMP), vaccine, aging, monocyte-derived dendritic cells (moDCs),
} tumor necrosis factor (TNF)

\section{INTRODUCTION}

The current COVID-19 pandemic has highlighted the vulnerability of aging populations to emerging pathogens where people 45 and older account for $\sim 97 \%$ of COVID-19 deaths (1). Vaccination offers the most efficient and cost-effective method to stop infectious diseases. However, vaccine efficacy is substantially reduced with age due to the progressive age-related decline of innate and adaptive immune responses (immunosenescence) (2-4). Immunosenescence also posts a significant challenge for the development of immunotherapeutic agents. The number of Americans ages 65 and older will double and reach 80 million in 2040 (5). Improving the efficacy of vaccines and immunotherapeutic agents in the aging population is critical to public health.

The biggest challenge in vaccination response in the aged is the inadequate antibody response $(6,7)$. Nevertheless, improving vaccine efficacy in the aged is achievable. For instance, while the efficacy of Prevnar $13^{\circledR}$ decreases with age (8) and is only $\sim 45 \%$ effective in adults 65 years or older (9), the Shingrix vaccine for shingles is $90 \%$ effective in people over 70 . The underlying mechanism behind the successful Shingrix in the aged, however, is unclear. Current vaccine strategies for the elderly are empirical. They include higher antigen dose, adjuvanted vaccine, and alternative route 
of immunization (10-12). We reasoned that mechanism-guided vaccine design could aid in the development of effective vaccines for the aged.

Cyclic dinucleotides (CDNs) are a promising class of vaccine adjuvants inducing potent, balanced, and longlasting humoral and cellular adjuvant responses for cancers and infectious diseases (13-15). CDNs include the bacterial second messenger, $3^{\prime}, 5^{\prime}$-cyclic diguanylic acid (cyclic di-GMP, CDG), cyclic di-AMP, mammalian second messenger 2'3'-cyclic GMP-AMP, and synthetic RpRpssCDA (15). Multiple clinical trials are ongoing to examine CDN efficacy in cancer immunotherapy (ClinicalTrials.gov NCT02675439, NCT03010176, NCT03172936, NCT03937141, and NCT0414414). Almost all studies on CDN adjuvanticity were done in young mice ( $<3$ months old). How aging influences $\mathrm{CDN}$ efficacy in vivo is not clear.

CDG was the founding member of $\mathrm{CDNs}$ and showed excellent vaccine efficacy in infectious diseases and immunotherapy (16-18). Mechanistically, CDG adjuvanticity depends on stimulator of interferon genes (STING)-induced tumor necrosis factor (TNF) production in vivo $(19,20)$ and is mediated by DCs (21). DCs are developmentally and functionally heterogeneous populations. We recently showed that CDG adjuvanticity is mediated by conventional DC2 (cDC2) and monocyte-derived DCs (moDCs) in vivo (22).

In this study, we examined CDG adjuvanticity in middle-aged and aged C57BL/6J mice. We further developed a mechanismguided moDC-targeting strategy to enhance CDG adjuvanticity in the middle-aged and aged mice.

\section{METHODS}

\section{Key Resources Table}

\begin{tabular}{|c|c|c|}
\hline REAGENT or RESOURCE & SOURCE & IDENTIFIER \\
\hline \multicolumn{3}{|l|}{ Antibodies } \\
\hline $\begin{array}{l}\text { Anti-mouse CD4-PE/Cy7 } \\
\text { (clone: GK1.5) }\end{array}$ & BioLegend & Cat\#100422 \\
\hline $\begin{array}{l}\text { Anti-mouse } \\
\text { CD45-PercP/Cy5.5 (clone: } \\
\text { 30-F11) }\end{array}$ & Biolegend & Cat\#103131 \\
\hline $\begin{array}{l}\text { Anti-mouse } \\
\text { MHCII(I-A/I-E)-Brilliant Violet } \\
421 \text { (clone: M5/114.15.2) }\end{array}$ & BioLegend & Cat\#107636 \\
\hline $\begin{array}{l}\text { Anti-mouse CD11c-APC/Cy7 } \\
\text { (clone: N418) }\end{array}$ & Bi olegend & Cat\#117323 \\
\hline $\begin{array}{l}\text { Anti-mouse/human } \\
\text { CD11b-PE/Cy7 (clone: } \\
\text { M1/70) }\end{array}$ & BioLegend & Cat\#101216 \\
\hline $\begin{array}{l}\text { Anti-mouse } \\
\text { CD64-PerCP/Cy5.5 (clone: } \\
\text { X54-5/7.1) }\end{array}$ & BioLegend & Cat\#139307 \\
\hline $\begin{array}{l}\text { Anti-mouse TNFR2-APC } \\
\text { (Clone: REA228) }\end{array}$ & $\begin{array}{l}\text { Miltenyi } \\
\text { Biotec }\end{array}$ & $\begin{array}{l}\text { Cat\#130-104- } \\
698\end{array}$ \\
\hline
\end{tabular}

(Continued)
Continued

\begin{tabular}{|c|c|c|}
\hline REAGENT or RESOURCE & SOURCE & IDENTIFIER \\
\hline $\begin{array}{l}\text { Anti-mouse PD1-FITC (Clone: } \\
\text { 29F.1A12) }\end{array}$ & BioLegend & Cat\#135214 \\
\hline $\begin{array}{l}\text { Anti-mouse/human pRelB-PE } \\
\text { (clone: D41B9) }\end{array}$ & $\begin{array}{l}\text { Cell Signaling } \\
\text { Technology }\end{array}$ & Cat\#:13567 \\
\hline $\begin{array}{l}\text { Anti-mouse CXCR5-APC } \\
\text { (clone: L138D7) }\end{array}$ & BioLegend & Cat\#145506 \\
\hline $\begin{array}{l}\text { Anti-mouse } \\
\text { CD19-PerCP/Cy5.5 (clone: } \\
\text { 1D3/CD19) }\end{array}$ & BioLegend & Cat\#152405 \\
\hline $\begin{array}{l}\text { Anti-mouse CD86-APC-Cy7 } \\
\text { (clone: GL-1) }\end{array}$ & BioLegend & Cat\#105029 \\
\hline Anti-mouse lgG2c-HRP & $\begin{array}{l}\text { Southern } \\
\text { Biotech }\end{array}$ & Cat\#1078-05 \\
\hline Anti-mouse lgG1-HRP & $\begin{array}{l}\text { Southern } \\
\text { Biotech }\end{array}$ & Cat\#1071-05 \\
\hline Anti-mouse IgG-HRP & $\begin{array}{l}\text { Southern } \\
\text { Biotech }\end{array}$ & Cat\#1033-05 \\
\hline Anti-mouse IgA-HRP & $\begin{array}{l}\text { Southern } \\
\text { Biotech }\end{array}$ & Cat\#1040-05 \\
\hline
\end{tabular}

Chemicals, Antigen, and ELISA kit

H1N1-nucleoprotein

SinoBiologica

cat\#11675-V08B

OVA

Invivogen

Cyclic di-GMP (vaccine-grade)

Invivogen

$\mathrm{NP}_{23}$-BSA

Biosearch

Technologies

Tissue protein extraction

ThermoFisher

Cat\#vac-pova

reagent (T-PER)

ACK lysis buffer

Thermofisher

Cat\# vac-nacdg

Cat\# N-5050H

$\mathrm{NP}_{2}$-BSA

Biosearch

Technologies

Protease inhibitors

Roche,

$\mathrm{NP}_{6} \mathrm{CGG}$

Biosearch

Technologies

TNF D221N/A223R $_{\text {-Fc (mouse }}$ IgG2A) fusion protein

Creative $^{\circledR}$

Biolabs

TNF-Fc (mouse lgG2A) fusion

protein

Creative $^{\circledR}$

Biolabs

Mouse TNF ELISA kit

ThermoFisher

Cat\#78510

Mouse IFN $\gamma$ ELISA kit

ThermoFisher

Mouse IL-17a ELISA kit

ThermoFisher

Mouse IL-13 ELISA kit

ThermoFisher

Cat\# A1049201

Cat\# N-5050XL

Cat\#11836153001

Cat\# N-5055A

Custom made

Custom made

Cat \# 88-7324-22

Cat \# 88-7314-22

Cat \# 88-8711-22

Experimental Models: Organisms/Strains

Mouse: CD11c Cre

Jackson

Laboratory

Mouse: IRF4 $4^{f / f \mid}$

Jackson

Laboratory

C57BL/6J

Jackson

Laboratory

Software and Algorithms

FlowJo version 10.1r1

FlowJo

http://www.flowjo. com

Prism6

GraphPad http://www. graphpad.com 


\section{Mice}

All mouse experiments were performed by the regulations and approval of the Institutional Animal Care and Use Committee from the University of Florida (IACUC no: 201909362). C57BL/6J mice were obtained, bred, maintained, and aged in the Animal Research Facility at the University of Florida. Both males and females were used to carry out the experiments.

\section{Immunization and Sample Collection}

For intranasal immunization, mice were immunized with protein antigen H1N1-nucleoprotein (NP), pneumococcal surface protein A (PspA), 4-hydroxy-3-nitrophenylacetyl hapten conjugated with chicken gamma globulin ( $\left.\mathrm{NP}_{6} \mathrm{CGG}\right)(1.5$ $\mu \mathrm{g} /$ mouse) alone or mixed with CDG (5 $\mu \mathrm{g} /$ mouse) and/or soluble TNF (solTNF)-Fc [immunoglobulin G2A (IgG2A)] (100 ng/mouse) and transmembrane TNF (tmTNF)-Fc (IgG2A) (100 $\mathrm{ng} /$ mouse) in total $40 \mu \mathrm{l}$ endotoxin-free phosphate buffered saline (PBS). Sera were collected after 30 and 60 days of the last immunization. Bronchoalveolar lavage fluid (BALF) was collected on day 60.

The TNF-Fc (IgG2A) (lot \# CB181108) and TNF $221 \mathrm{~N} / \mathrm{A}_{223 R^{-}}$ Fc (IgG2A) (lot \# CB190829) fusion proteins were made by Creative ${ }^{\circledR}$ Biolabs. The fusion protein has $\mathrm{N}$-Terminal Histidine tag. They were expressed in $\mathrm{CHO}$ cells and purified with affinity chromatography. The purity is $>95 \%$ as determined by sodium dodecyl sulfate (SDS)-polyacrylamide gel electrophoresis (PAGE) (Coomassie blue densitometry). Endotoxin level of the fusion proteins is less than $0.5 \mathrm{EU} / \mathrm{mg}$ fusion protein.

The following reagent was obtained through BEI Resources, National Institute of Allergy and Infectious Diseases (NIAID), National Institutes of Health (NIH): Streptococcus pneumoniae Family 2, Clade 3 Pneumococcal Surface Protein A (PspA UAB099) with C-Terminal Histidine Tag, Recombinant from Escherichia coli, NR-33179.

\section{Antibody ELISA}

A 96-well, flat-bottomed polystyrene plate was coated with 500 ng of H1N1-NP, PspA, or $\mathrm{NP}_{2} \mathrm{BSA}, \mathrm{NP}_{23} \mathrm{BSA}$, washed with 1 $\times$ PBS with Tween 20 (PBST), blocked with $2 \%$ bovine serum albumin (BSA) in $1 \times \mathrm{PBS}$, and incubated at $37^{\circ} \mathrm{C}$ (20). After wash, serum samples were serially diluted in PBS, added to the wells in triplicate, and incubated at $37^{\circ} \mathrm{C}$ for $1 \mathrm{~h}$. The plate was washed. Horseradish peroxidase (HRP)-conjugated anti-mouse IgG/IgG1/IgG2c/IgA was added at a dilution of $1: 5,000$ and incubated at $37^{\circ} \mathrm{C}$ for $1 \mathrm{~h}$. After washing, $3,3^{\prime}, 5,5^{\prime}-$ tetramethylbenzidine (TMB) substrate reagent was added and incubated for $20 \mathrm{~min}$ in the dark. The reaction was stopped using $50 \mu \mathrm{l}$ of stop solution, and absorbance reading noted at $450 \mathrm{~nm}$.

\section{Ex-vivo Recall of Lung Cells and Splenocytes}

Lung and spleen cells were harvested and digested as before (21). The cells were resuspended in RPMI media containing $10 \%$ fetal bovine serum (FBS) in a 96-well tissue culture plate at a concentration of $1 \times 10^{6} /$ well. The cells were stimulated with 1 $\mu \mathrm{g} \mathrm{H} 1 \mathrm{~N} 1-\mathrm{NP}$ or $2 \mu \mathrm{g} \mathrm{NP}{ }_{6} \mathrm{CGG}$ and incubated for 4 days at $37^{\circ} \mathrm{C}$ and $5 \% \mathrm{CO}_{2}$. Culture supernatants were collected, and cytokine levels were evaluated for interleukin (IL)-13, IL-5, interferon (IFN) $-\gamma$, and IL-17a by ELISA.

\section{Flow Cytometry}

Lungs were harvested and processed as discussed above. The single-cell suspension was prepared and analyzed by $\mathrm{BD}^{\mathrm{TM}} \mathrm{LSR}$ II and FACScan flow cytometry (21).

\section{Gating Strategy for Lung Dendritic Cells}

cDC1 are $\mathrm{MHCII}^{\mathrm{hi}} \mathrm{CD} 11 \mathrm{c}^{+} \mathrm{CD} 11 \mathrm{~b}^{-} \mathrm{CD}^{-} 4^{-}$, moDCs are $\mathrm{MHCII}^{\mathrm{hi}} \mathrm{CD} 11 \mathrm{c}^{+} \mathrm{CD} 11 \mathrm{~b}^{+} \mathrm{CD}_{4}{ }^{+}$, and $\mathrm{CDC} 2$ are $\mathrm{MHCII}^{\text {hi }} \mathrm{CD} 11 \mathrm{c}^{+} \mathrm{CD} 11 \mathrm{~b}^{+} \mathrm{CD}^{-}$(21). Antibody stain was performed at $4^{\circ} \mathrm{C}$ for $20 \mathrm{~min}$. Please see the Key Resources section above for a detailed list of antibodies used.

\section{Detection of Lung Tumor Necrosis Factor}

Mice were intranasally immunized with either PBS or CDG $(5 \mu \mathrm{g})$ and sacrificed after $5 \mathrm{~h}$ by $\mathrm{CO}_{2}$ asphyxiation. Lungs were perfused with ice-cold PBS, removed and stored in $0.7 \mathrm{ml}$ Tissue Protein Extraction Reagent (T-PER) containing protease inhibitors at $-80^{\circ} \mathrm{C}$. Later, the lung was thawed on ice and homogenized with Minilys ${ }^{\circledR}$ (Precellys, 5,000 RPM for $30 \mathrm{~s}$ ) using Precellys lysing kit. Lung homogenates were transferred to a $1.5-\mathrm{ml}$ tube and harvested at $14,000 \mathrm{~g}$ for $30 \mathrm{~min}$ at $4^{\circ} \mathrm{C}$. The supernatant was collected and analyzed for TNF production by ELISA.

\section{Statistical Analysis}

GraphPad Prism v6.05 software was used for data preparation and statistical analysis. One-way or two-way ANOVA followed by Tukey's multiple comparison tests were employed. $p<0.05$ was considered significant. ${ }^{*}<0.05,{ }^{* *}<0.01,{ }^{* * *}<0.001,{ }^{* * * *}$ $<0.0001$. n.s. represents non-significant.

\section{Experimental Design}

Data exclusion was justified when positive or negative control did not work. All experiments will be repeated at least three times. All repeats are biological replications that involve the same experimental procedures on different mice. Experiments comparing different genotypes, adjuvant responses are designed with individual treatments being assigned randomly. Where possible, treatments will be assigned blindly to the experimenter by another individual in the lab. When comparing samples from different groups, samples from each group will be analyzed in concert, thereby preventing any biases that may arise from analyzing individual treatments on different days.

\section{RESULTS}

\section{3',5'-Cyclic Diguanylic Acid Adjuvant Activity Is Impaired in Aged Mice}

CDG induces balanced, potent, and long-lasting vaccine adjuvant responses in young animals $(16,20-22)$. To investigate the influence of aging, we compared CDG adjuvanticity in 18month-old aged and 3-month-old adult C57BL/6J mice. Mice were immunized [intranasally (i.n.)] with CDG/H1N1- NP twice at a 2 -week interval. Serum anti-H1N1-NP antibody titer was 
determined on days 30 and 60 after the last immunization. Unexpectedly, aged mice showed significantly ( $\sim 10$-folds) reduction of anti-H1N1-NP IgG titer $(p<0.0001 ; p<0.001)$ than the adult mice (Figures 1A-F). Similarly, on day 60, IgA antibody titer in BALF was significantly lower $(\sim 5$-folds, $p<0.0001)$ in aged mice than the adult mice.

CDG immunization generates potent and long-lasting memory $\mathrm{T}$ helper (Th)1, Th2, Th17 response in adult mice $(16,20-22)$. However, ex vivo recall assay showed that 60 days post-immunization, aged mice had dramatically (10folds) reduced memory Th1 and Th17 responses in the lung (Figure 1G). The lung memory Th2 responses were also reduced by half (Figure 1G). CDG induced lung T follicular helper (TFH), which is critical for its adjuvant responses (22). We examined lung TFH cells on day 14 post-immunization. Lungs from immunized aged mice showed a 10 -fold reduction of CXCR5 ${ }^{+}$ $\mathrm{PD}^{+} \mathrm{CD}^{+} \mathrm{TFH}$ cells than the adult mice (Figure $\mathbf{1 H}$ ). Together, the data indicated that CDG adjuvanticity was impaired in the aged mice.

\section{3',5'-Cyclic Diguanylic Acid Did Not Activate Lung TNFR2+ ${ }^{+}$CD2 or Monocyte-Derived Dendritic Cells in Aged Mice}

CDG activates lung DCs to mediate its adjuvanticity in vivo (21). The lung DCs are functionally heterogeneous. In particular, lung $\mathrm{CDC} 2$ and moDCs play a pivotal role in the CDG vaccine adjuvanticity (22). We found that aged mice had increased moDCs in the lung (Figures 2A,B). On the other hand, lung CDC2 was decreased in the aged mice, but the difference was not significant (Figures 2A,B). cDC2 consists of functionally distinct TNFR2 $^{+}$and TNFR2 ${ }^{-}$cDC2 subsets (22). The TNFR2 ${ }^{+}$cDC2 subset (R2D2) mediates the cellular immune responses of CDG adjuvant, while the TNFR2 ${ }^{-}$CDC2 subset activates moDCs to mediate the humoral responses of CDG (22). Interestingly, lung R2D2 population was significantly decreased in the aged mice (Figure 2C).

Next, we examined CDG-induced lung DC activation in the aged mice. Intranasal administration of CDG did not activate lung R2D2 or moDCs in the aged mice, as indicated by the lack of CD86 upregulation (Figures 2D,E). CDG activates lung cDC2 to produce lung TNF (Figure $2 \mathrm{~F}$ ) that is critical for CDG adjuvanticity $(19,20,22)$. We measured lung TNF in aged and adult mice. We first noticed that aged mice had elevated lung TNF levels compared to adult mice at steady state (Figure 2F). Second, CDG did not increase lung TNF production in the aged mice (Figure 2F), suggesting that lung $\mathrm{CDC} 2$ from the aged mice is defective in response to CDG.

Last, TNFR2 expression on moDCs is essential for CDG adjuvanticity in vivo (22). Consistently, CDG induced less lung TNFR2 ${ }^{+}$moDCs in the aged mice than the adult mice (Figure S1A). TNFR2 signals via the non-canonical nuclear factor (NF)- $\kappa$ B pathway RelB. Again, CDG-induced pRelB was reduced in lung moDCs from the aged mice (Figure S1B). Together, the data suggested that CDG-induced lung R2D2 or moDC activation was impaired in the aged mice.

\section{3',5'-Cyclic Diguanylic Acid-Induced Th1 and Th17 Responses Were Impaired in the 1-Year-Old Middle-Aged Mice}

Adult mice ( $\sim 3$ months old), not aged mice ( $\sim 18$ months old), exhibit potent CDG-induced humoral and cellular responses (Figure 1). We asked at what age CDG adjuvant responses start to wane. We examined the 1-year-old mice, which are the equivalent of $\sim 42.5$-year-old middle-aged humans. We immunized 1-yearold mice with $\mathrm{CDG} / \mathrm{NP}_{6} \mathrm{CGG}$ twice at 2 weeks' interval and examined antibody and memory Th responses after 60 days. We chose antigen $\mathrm{NP}_{6} \mathrm{CGG}$ so that we can separate vaccineinduced low-affinity (anti- $\mathrm{NP}_{23}$ ) and high-affinity (anti- $\mathrm{NP}_{2}$ ) antigen-specific antibodies influenced by aging. High-affinity antibody formation is a hallmark of germinal center formation and provides rapid neutralization of extracellular pathogens.

Surprisingly, while CDG still induced antigen-specific Th2 responses in the lung of 1-year-old mice (Figure 3B; Figure S2A), CDG barely induced lung memory Th1 or Th17 responses in the 1-year-old mice (Figures 3A,C). Consistently, CDG induced antigen-specific IgG1, but not Th1-related IgG2C in the 1-year-old mice (Figures S2B,C). Next, we examined the high- and low-affinity antibodies in CDG-immunized 1year-old mice. We found that CDG did not induce high-affinity lung IgA in the 1-year-old mice (Figures 3K,L). CDG still induced low-affinity lung IgA (Figures 3I,J). We reasoned that 1 -year-old mice might be defective in CDG-induced antibody affinity maturation in the lung. In the serum, CDG induced low-affinity IgG, but the titers of high-affinity IgG was low (Figures 3E,F,G,H). The data, thus, suggested that CDG-induced memory Th1, Th17 responses, and high-affinity antibody production were impaired in the 1-year-old middle-aged mice.

\section{Design a Monocyte-Derived Dendritic Cell-Targeting TNF-Fusion Protein to Enhance 3',5'-Cyclic Diguanylic Acid Adjuvant Responses in Aging Mice}

The discovery that 1-year-old healthy mice already had waning CDG vaccine response was potentially significant in the translational research of CDNs. The median age for COVID19 patients in the US is $\sim 63$ years old (23). The median age for pneumococcal meningitis patients is 41 years old (24). The median age for a recent $\mathrm{CDN}$ cancer clinical trial was 61 years old (ClinicalTrials.gov NCT02675439). Here, we discovered that CDG adjuvanticity depends on age. To translate CDG research into the clinic, we need methods to improve CDG adjuvanticity in aging humans.

MoDC activation is essential for CDG adjuvanticity (22). Aged mice had defective moDC activation, but their numbers increased (Figure 2). Meanwhile, lung TNF, including solTNF, and tmTNF, mediates CDG adjuvanticity by activating moDCs $(20,22)$. Last, aged mice had impaired CDG-induced lung TNF (Figure 2). We hypothesized that supplementing moDCtargeting solTNF and tmTNF might enhance CDG adjuvanticity in aging mice.

We generated TNF-Fc (IgG2A) and TNF$_{\mathrm{D} 221 \mathrm{~N} / \mathrm{A} 223 \mathrm{R}-\mathrm{Fc}}$ (IgG2A) fusion proteins to target solTNF or tmTNF to moDCs 


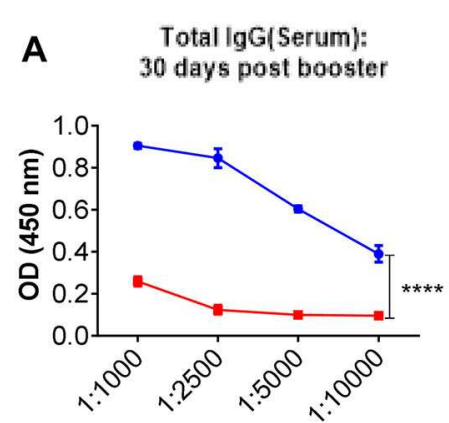

Antibody dilution

- Aged mice (CDG/NP)

- Adult mice (CDG/NP)

B Total lgG(Serum): 30 days post booster

(11 fold reduction)

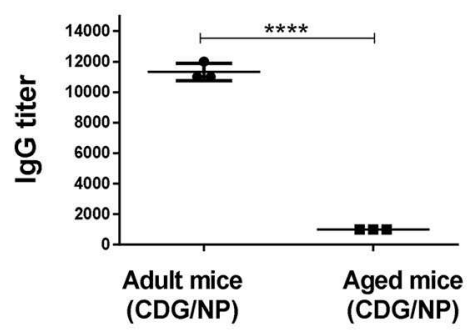

Th1

$\mathbf{G}$

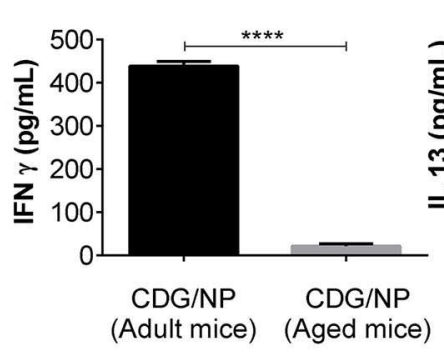

H Lung CD4 ${ }^{+}$T Cells (CDG/OVA)

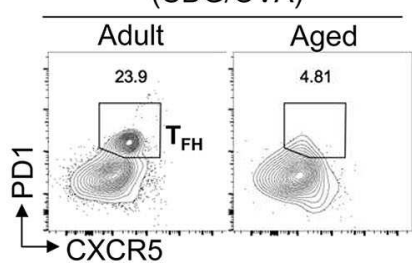

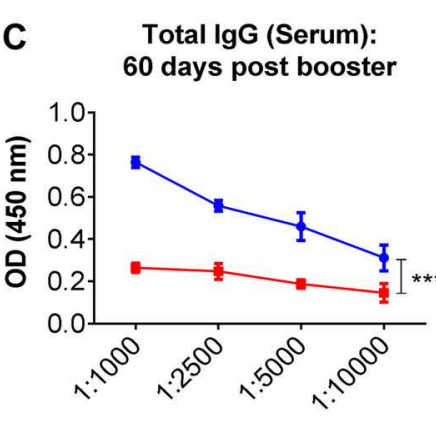

Antibody dilution

- Aged mice (CDG/NP)

- Adult mice (CDG/NP)

D

Total IgG (Serum): 60 days post booster (10 fold reduction)

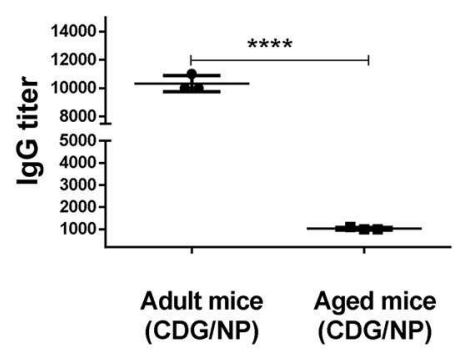

Lung ex vivo recall

Th2

IL 13(Lung)
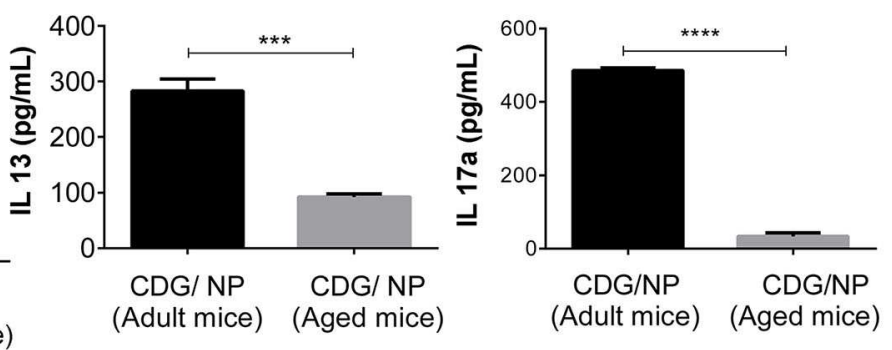

IgA (BALF):

60 days post booster

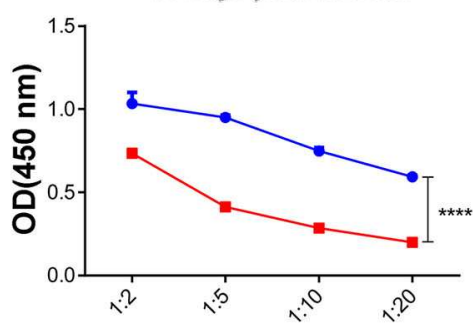

Antibody dilution

- Aged mice (CDG/NP)

- Adult mice (CDG/NP)

\section{F}

IgA (BALF):

60 days post booster

(5.5 fold reduction)

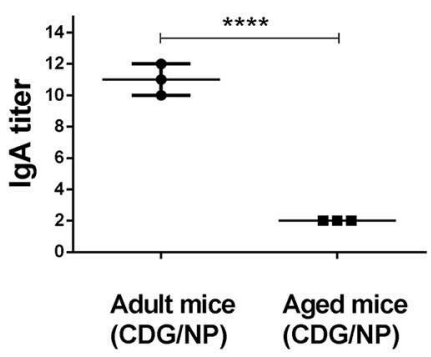

Th17

IL17a (Lung)

FIGURE 1 | 3',5'-Cyclic diguanylic acid (cyclic di-GMP, CDG) adjuvanticity is decreased in aged mice. (A-F) Adult ( 3-month-old) and aged ( 18-month-old) C57BL/6 wild-type (WT) mice ( $n=4$ mice/group) were immunized intranasally (i.n.) with CDG (5 $\mu$ g) plus influenza nucleoprotein (NP) (1.5 $\mu$ g) on days 0 and 14. Antibody titers were determined from serum (day 30 and 60) and bronchoalveolar lavage fluid (BALF) samples 60 days post the last immunization. Immunoglobulin (Ig)G and IgA endpoint titers were determined by comparing the OD450 from adult immunized mice with aged immunized mice. Data are representative of three independent experiments. (G) Lung cells from the immunized mice in (A) were recalled with NP (1 $\mu$ g) ex vivo conditions for 4 days. Th17, Th1, and Th2 cytokines 
FIGURE 1 | were measured in the culture supernatant. Data are representative of three independent experiments. (H) Flow cytometry analysis of $\mathrm{T}$ follicular helper (TFH) formation in lung cells of adult and aged C57BL/6 mice on day 14 post CDG (5 $\mu$ g)/ovalbumin (OVA) (1.5 $\mu$ g) immunization (i.n.). ( $n=4$ mice/group). Data are representative of three independent experiments. Significance value, $p$, for (A-F) was calculated between adult and aged mice groups using two-way ANOVA followed by Tukey's multiple comparison test $(\mathbf{A}, \mathbf{C}, \mathbf{E})$ and Student's $t$-test $(\mathbf{B}, \mathbf{D}, \mathbf{F})$. Significance value, $p$, for $(\mathbf{G}, \mathbf{H})$ was calculated between adult and aged mice groups using one-way ANOVA followed by Tukey's multiple comparison test. Error bars represent mean \pm SEM. Statistical significance is represented by $p$; ${ }^{\star *} p<0.01,{ }^{\star \star \star} p<0.001,{ }^{\star \star \star *} p<0.0001$.

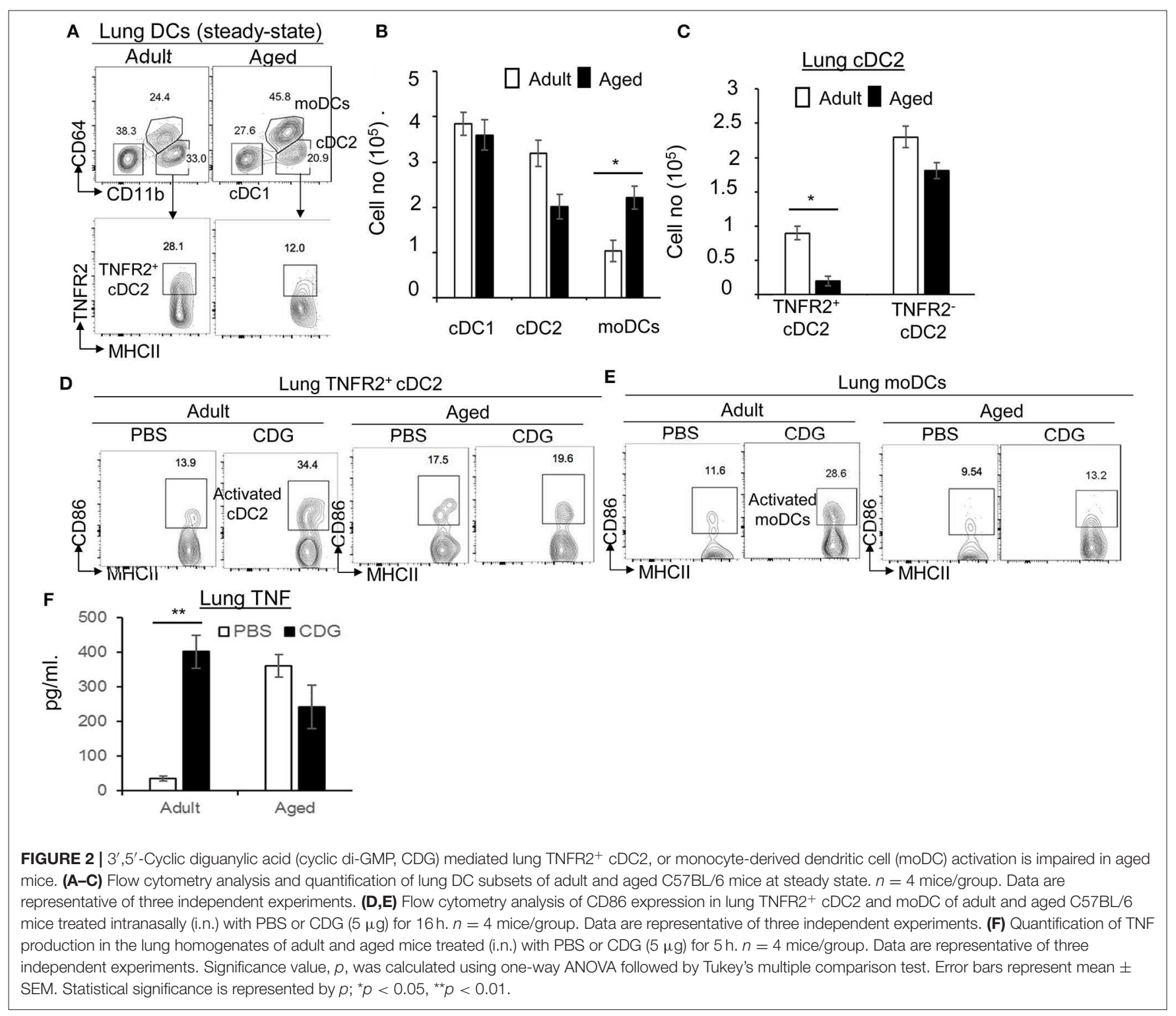

(Figure 3D). The $\mathrm{TNF}_{\mathrm{D} 221 \mathrm{~N} / \mathrm{A} 223 \mathrm{R}}$ mutant mimics tmTNF that binds only to TNFR2, not TNFR1 (25). MoDCs express the highaffinity FcR, Fc $\gamma$ RI (also known as CD64) that is not found on cDCs or lymphocytes (26). Fc $\gamma$ RI bind the Fc of IgG2a with the highest affinity $\left(10^{8} \mathrm{M}^{-1}\right)$, more than 1,000-fold higher than its next binding partner IgG2b-Fc (27). We showed that intranasal administration of allophycocyanin (APC)-conjugated mouse IgG2A was taken up exclusively by $\mathrm{CD} 64^{+}$lung cells, including MHC II ${ }^{\mathrm{hi}} \mathrm{CD} 64^{+}$moDCs (28). The $\mathrm{CD}^{+} 4^{+}$major histocompatibility complex (MHC) class II ${ }^{\text {low/int }}$ macrophages were also targeted (28). However, macrophages are dispensable for CDG mucosal adjuvanticity in vivo $(21,22)$.

To test the efficacy of moDC-targeting TNF fusion proteins, we used the $\mathrm{IRF} 4^{\mathrm{I} / \mathrm{l} / \mathrm{CD}} 11 \mathrm{c}^{\text {cre }}$ mice. CDG does not generate lung $\mathrm{TNF}$ or vaccine responses in the $\mathrm{IRF} 4^{\mathrm{Il} / \mathrm{fl}} \mathrm{CD} 11 \mathrm{c}^{\text {cre }}(22)$, thus facilitated the TNF fusion proteins complement experiment. Furthermore, IRF4 ${ }^{\mathrm{fl} / \mathrm{fl}} \mathrm{CD} 11 c^{\mathrm{cre}}$ mice only have $\mathrm{cDCl}$ and moDCs. cDC1 is dispensable for CDG adjuvanticity (22). If 


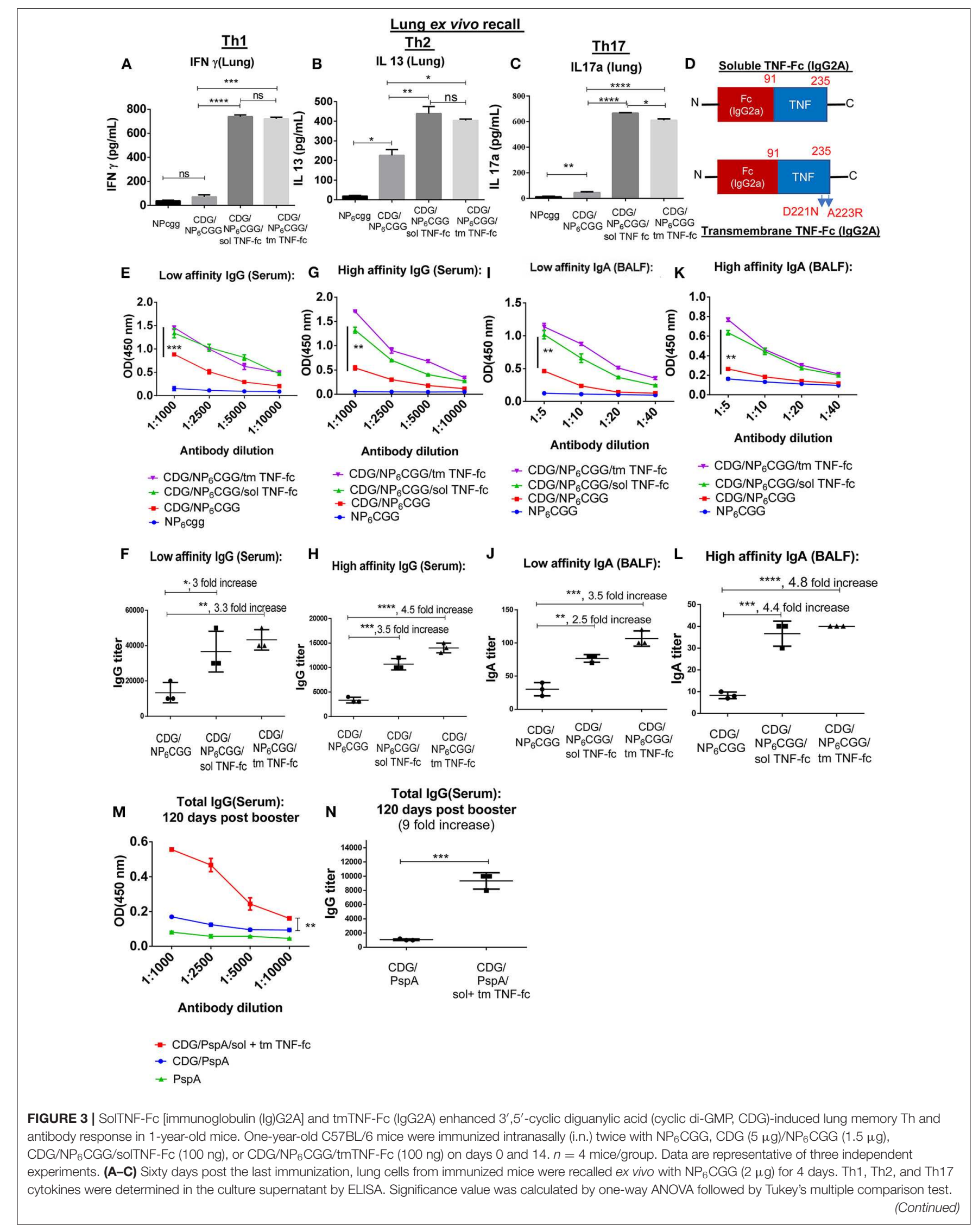


FIGURE 3 | Error bar represents mean \pm SEM. ${ }^{* \star} p<0.01,{ }^{* \star *} p<0.001$. (D) A cartoon of the moDC-targeting TNF fusion proteins. (E-L) Serum and bronchoalveolar lavage fluid (BALF) samples were collected from mice in (A) and analyzed for NP-specific antibody titers by ELISA. IgG and IgA endpoint titers were determined by comparing the OD450 from mice immunized with NP 6 CGG. Significance value was calculated by two- way ANOVA followed by Tukey's multiple comparison test. Error bar represents mean \pm SEM. ${ }^{\star} p<0.05$, ${ }^{\star \star} p<0.01$, ${ }^{\star \star \star} p<0.001$, ${ }^{\star \star \star \star} p<0.0001$, n.s., not significant. (M,N) One-year-old C57BL/6 mice were immunized (i.n.) twice with PspA, CDG/PspA, or CDG/PspA/(solTNF-Fc + tmTNF-Fc) on days 0 and 14. Serum samples were collected 120 days post last immunization, and anti-PspA specific antibody titer was determined by ELISA (M). Antibody titer was quantified by comparing the OD450 of immunized mice with PspA only immunized mice (N). $n=4$ mice/group. Data are representative of three independent experiments. Significance value was calculated by two-way ANOVA followed by Tukey's multiple comparison test (M) or Student's $t$-test $(\mathbf{N})$. Error bar represents mean \pm SEM. ${ }^{* \star} p<0.01,{ }^{* \star *} p<0.001$.

either solTNF-Fc or tmTNF-Fc restores antibody responses in the IRF $4{ }^{\mathrm{f} / \mathrm{fl}} \mathrm{CD} 11 \mathrm{c}^{\text {cre }}$ mice, it will strongly suggest that these TNF fusion proteins act through moDCs to enhance CDG adjuvanticity in vivo.

We found that intranasal administration of tmTNF-Fc (IgG2A) plus CDG generated high-affinity serum IgG antibody in the IRF $4{ }^{\mathrm{fl} / \mathrm{fl}} \mathrm{CD} 11 c^{\mathrm{cre}}$ mice (Figure S3), suggesting that tmTNFFc (IgG2A) can enhance CDG-induced humoral response in the absence of $\mathrm{cDC} 2$. This is an important feature as we showed that aged mice had a decreased number of cDC2, especially R2D2 that is critical for CDG adjuvanticity. Thus, tmTNF-Fc (IgG2A) may be suitable to enhance CDG antibody responses in the aged mice where lung R2D2 is limited.

SolTNF-Fc (IgG2A) did not restore CDG-induced antibody responses in the $\mathrm{IRF} 4^{\mathrm{fl} / \mathrm{fl}} \mathrm{CD} 11 c^{\text {cre }}$ mice (Figure S3). This was consistent with the previous finding that TNFR2 expression of moDCs is important for CDG-induced lung TFH cells and GC (Germinal Center) B cell production (22). Last, as expected, neither tmTNF-Fc (IgG2A) nor solTNF-Fc (IgG2A) restored the memory Th responses in the IRF $4^{\mathrm{fl} / \mathrm{fl}} \mathrm{CD} 11 \mathrm{c}^{\text {cre }}$ mice (28) as we previously demonstrated that R2D2 is required for CDG-induced cellular immunity (22).

\section{Monocyte-Derived Dendritic Cell-Targeting SoITNF and TmTNF Enhances $3^{\prime}, 5^{\prime}$-Cyclic Diguanylic Acid Adjuvant Responses in 1-Year-Old Mice}

Next, we determined if tmTNF-Fc (IgG2A) or solTNF-Fc (IgG2A) can enhance CDG adjuvanticity in 1-year-old middleaged $\mathrm{C} 57 \mathrm{BL} / 6 \mathrm{~J}$ mice. Again, we used the model antigen $\mathrm{NP}_{6} \mathrm{CGG}$ to separate high- vs. low-affinity antibodies by immunization. We immunized 1-year-old C57BL/6J mice with $\mathrm{NP}_{6} \mathrm{CGG}$ alone, $\mathrm{CDG} / \mathrm{NP}_{6} \mathrm{CGG}$, or $\mathrm{CDG} / \mathrm{NP}_{6} \mathrm{CGG}$ with solTNF-Fc or tmTNF-Fc twice at a 2-week interval. Lung memory $\mathrm{T}$ cell responses were determined by ex vivo recall assay 60 days post the last immunization. Remarkably, both solTNF-Fc and tmTNF-Fc restored CDG-induced lung memory Th1 and Th17 responses in the 1-year-old C57BL/6J mice (Figures 3A,C). The moDC-targeting TNF fusion proteins did not affect lung memory Th2 responses much in the 1-year-old mice (Figure 3B; Figure S2A). Consistently, the moDC-targeting TNF fusion proteins increased lung IgG2c production (Figure S2C). The 1-year-old mice were defective in generating high-affinity antibodies by CDG adjuvant (Figures 3G,K). We found that both solTNF-Fc and tmTNF-Fc enhanced CDG-induced antibodies, especially high-affinity antigen-specific antibodies in the 1-year-old mice (Figures 3G,H,K,L).

Last, we immunized (i.n.) 1-year-old mice with CDGadjuvanted mucosal pneumococcal protein subunit vaccine CDG/PspA with or without TNF-Fc fusion proteins twice at 2 weeks' interval. Serum anti-PspA IgG was determined 120 days post the last immunization. Remarkably, 1-year-old mice immunized with CDG/PspA plus TNF-Fc fusion proteins had stronger serum anti-PspA IgG 4 months post-immunization than the 1-year-old mice immunized with only CDG/PspA (Figures 3M,N). Together, the data indicated that the moDCtargeting TNF fusion proteins restored the memory Th1, Th17, and high-affinity antibody production in CDG-immunized 1year-old middle-aged C57BL/6J mice.

Intranasal administration of TNF elicits antibody and Th2 responses (29). However, intranasal administration of solTNFFc (IgG2A) or tmTNF-Fc (IgG2A) alone did not induce any antibody or memory Th responses (Figure S4), indicating that the moDC-targeting TNF fusion proteins enhanced CDG adjuvant responses, rather than producing vaccine responses de novo. We used a much lower dose of TNF-Fc (IgG2a) (100 ng) than previous TNF $(2 \mu \mathrm{g})$ used as a mucosal adjuvant (29).

\section{SolTNF-Fc (IgG2A) and TmTNF-Fc (IgG2A) Enhance 3',5'-Cyclic Diguanylic Acid-Induced Systemic and Mucosal Antibody Responses in 2-Year-Old C57BL/6J Mice}

Next, we used moDC-targeting TNF fusion proteins to restore CDG adjuvanticity in 2-year-old mice that are equal to $\sim 70$-yearold humans. We immunized (i.n.) 2-year-old C57BL/6J mice with $\mathrm{NP}_{6} \mathrm{CGG}$ alone, $\mathrm{CDG} / \mathrm{NP}_{6} \mathrm{CGG}$, or $\mathrm{CDG} / \mathrm{NP}_{6} \mathrm{CGG}$ with solTNF-Fc (IgG2A) and tmTNF-Fc (IgG2A) twice at a month's interval. Serum antigen-specific antibodies were determined in the serum on days 30 and 60 post last immunization. As expected, CDG did not induce durable and high-affinity IgG in the aged mice (Figures 4A,C,E; Figures S4A-C). In contrast, the addition of solTNF-Fc (IgG2A) and tmTNF-Fc (IgG2A) generated durable serum antigen-specific serum IgG in the 2year-old mice (Figures 4A-F) $(p<0.0001)$. The enhancement of antibody production was across the spectrum, including augmented production of IgG1, IgG2C by moDC-targeting TNF fusion proteins (Figures S4A,B). We also determined the affinity 
A

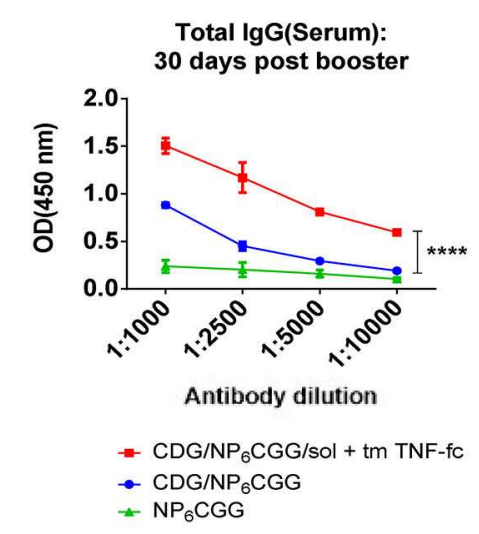

B

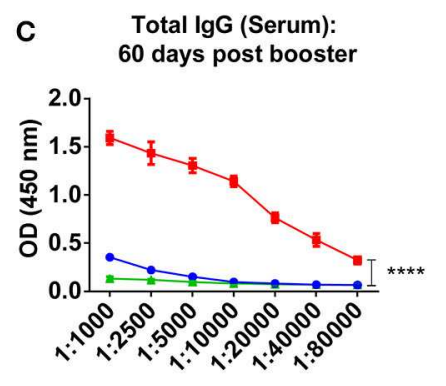

Antibody dilution

- CDG/NP 6 cgg/ sol + tm TNF- fc - $\mathrm{CDG} / \mathrm{NP}_{6} \mathrm{cgg}$ $-\mathrm{NP}_{6} \mathrm{cgg}$
E High affinity lgG (Serum): 60 days post booster

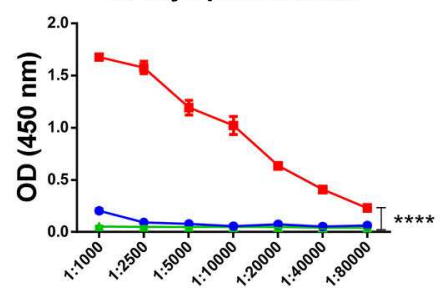

Antibody dilution

$-\mathrm{CDG} / \mathrm{NP}_{6} \mathrm{cgg} / \mathrm{sol}+\mathrm{tm}$ TNF-fc

$\rightarrow \mathrm{CDG} / \mathrm{NP}_{6} \mathrm{Cgg}$

$₫ \mathrm{NP}_{6} \mathrm{cgg}$
D
Total IgG (Serum): 60 days post booster (73 fold increase)

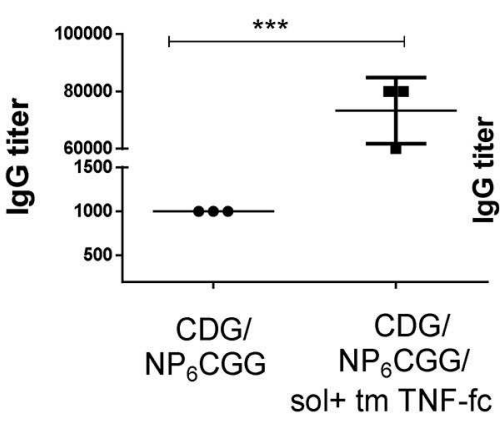

High affinity IgG (Serum): 60 days post booster (92.5 fold increase)
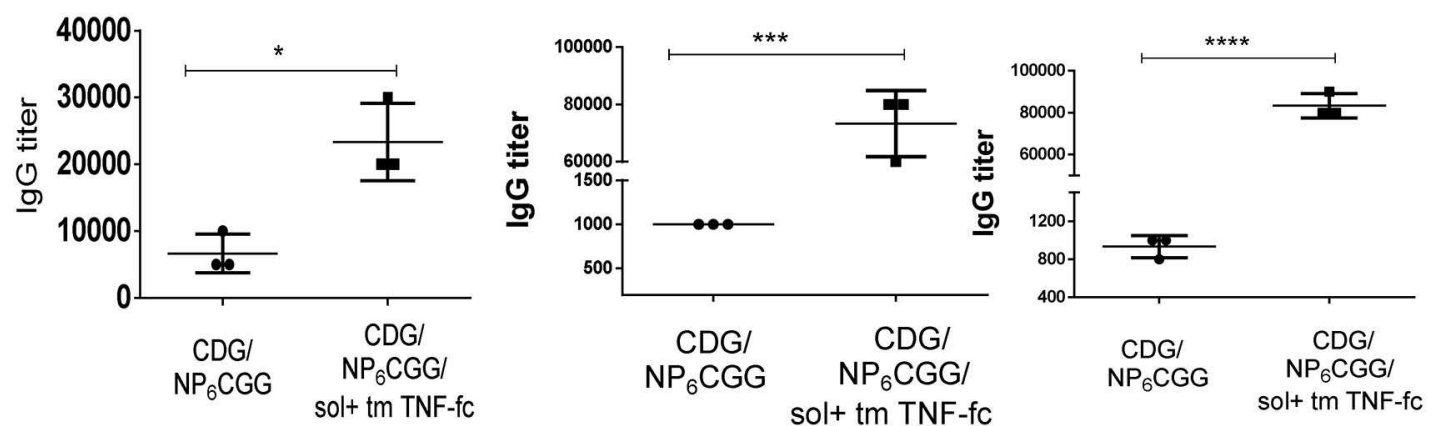

G

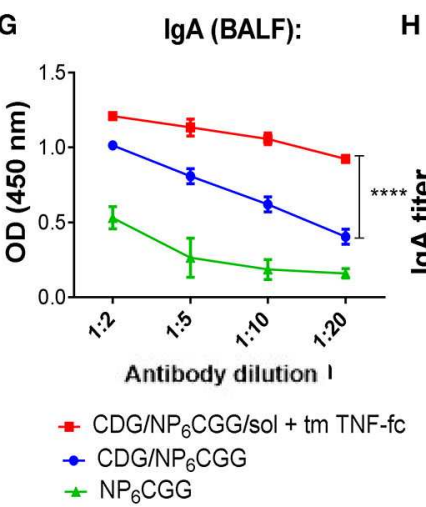

H

$\operatorname{lgA}$ (BALF): (2.5 fold increase)

\section{I}

High affinity IgA (BALF):

High affinity $\lg A$ (BALF):
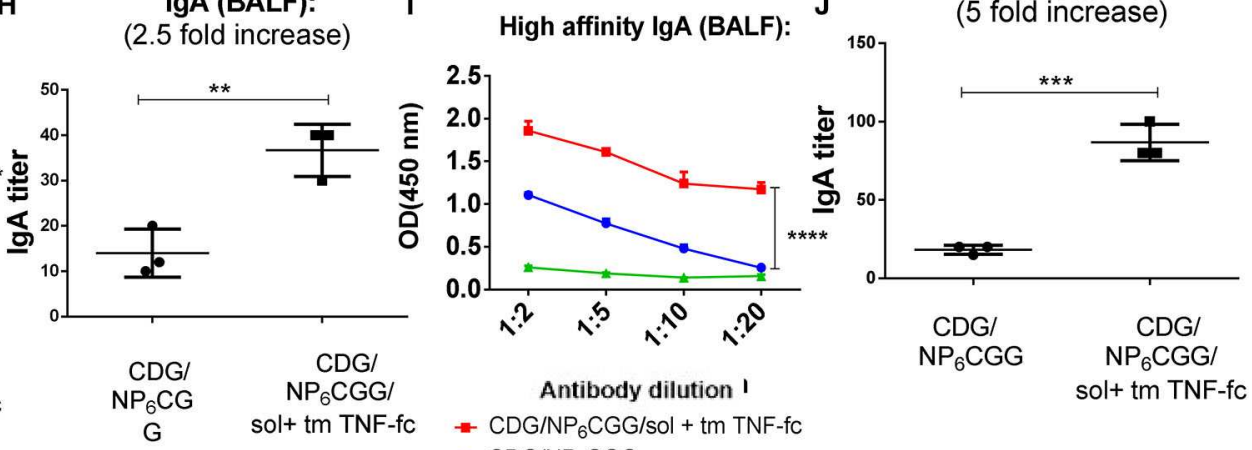

- CDG/NP 6 CGG/sol + tm TNF-fC

- $\mathrm{CDG} / \mathrm{NP}_{6} \mathrm{CGG}$

$\Rightarrow \mathrm{NP}_{6} \mathrm{CGG}$

FIGURE 4 | SolTNF-Fc [immunoglobulin (Ig)G2A] and tmTNF-Fc (IgG2A) enhanced 3',5'-cyclic diguanylic acid (cyclic di-GMP, CDG)-induced humoral response in 2-year-old mice. Two-year-old C57BL/6 mice were intranasally (i.n.) immunized with NP 6 CGG, CDG/NP 6 CGG, or CDG/NP 6 CGG/solTNF-Fc (IgG2A) + tmTNF-Fc (IgG2A) on days 0 and 30. $n=4$ mice/group. Data are representative of three independent experiments. (A-F) Serum samples were collected on 30 and 60 days after the last immunization and total IgG, high-affinity IgG titer were determined by ELISA. (G-J) Total IgA, high-affinity IgA in bronchoalveolar lavage fluid (BALF) from immunized mice in (A) were determined by ELISA. Antibody endpoint titer was determined by comparing the mice immunized with NP ${ }_{6}$ CGG. Significance value was calculated by two-way ANOVA followed by Tukey's multiple comparison test. Error bar represents mean \pm SEM. ${ }^{\star *} p<0.05,{ }^{{ }^{*}} p<0.01,{ }^{{ }^{\star \star *}} p<0.001,{ }^{\star \star \star \star} p<0.0001$.

of the antigen-specific antibody titer in the 2-year-old mice and observed that solTNF-Fc (IgG2A) and tmTNF-Fc (IgG2A) dramatically enhanced (92-folds) CDG-mediated high-affinity antibody production in 2-year-old mice (Figures $4 \mathrm{E}, \mathrm{F})$. Last, the enhancement of TNF-Fc fusion proteins was stronger on day 60 (73-folds) than on day 30 (3-folds) post-immunization
(Figures 4B,D), suggesting that the TNF-Fc fusion protein increased the durability of serum IgG production in 2-yearold mice.

The induction of antigen-specific IgA response in the lung is highly desirable for preventing respiratory infections such as influenza, S. pneumococcal, and SARS-CoV infections. The 
vast majority of licensed vaccines do not generate lung mucosal IgA responses, even in healthy adults. CDG-adjuvanted vaccines induce antigen-specific lung IgA in the adult but not aged mice (Figure 1C). We next examined if the moDC-targeting TNF fusion proteins restored lung IgA production in the aged mice. We collected BALF from the $\mathrm{CDG} / \mathrm{NP}_{6} \mathrm{CGG}$ or CDG/NP6CGG + solTNF-Fc + tmTNF-Fc immunized (i.n.) 2year-old $\mathrm{C} 57 \mathrm{BL} / 6 \mathrm{~J}$ mice 60 days post the last immunization and determined antigen-specific IgA titer including high-affinity IgA. A significant elevation in the IgA titer was observed in aged mice immunized with $\mathrm{CDG} / \mathrm{NP}_{6} \mathrm{CGG}$ adjuvanted with solTNF-Fc (IgG2A) and tmTNF-Fc (IgG2A) as compared to the mice group immunized with only $\mathrm{CDG} / \mathrm{NP}_{6} \mathrm{CGG}(p<$ 0.0001) (Figures 4G,H; Figure S4D). Further analysis showed $\mathrm{CDG} / \mathrm{NP}_{6} \mathrm{CGG}$ elicited primarily low-affinity lung IgA titer while $\mathrm{CDG} / \mathrm{NP}_{6} \mathrm{CGG}$ with moDC-targeting TNF fusion proteins generated high-affinity lung IgA $(p<0.0001)$ in the 2 -year-old mice (Figures $4 \mathbf{I}, \mathbf{J}$ ).

Together, the data indicated that the moDC-targeting TNF fusion proteins markedly enhanced CDG-induced durable and high-affinity antibody responses, both in the serum and in the lung, in the 2-year-old C57BL/6J mice.

\section{SolTNF-Fc (IgG2A) and TmTNF-Fc (IgG2A) Restores Systemic and Lung Memory Th1, Th17 Responses in $3^{\prime}, 5^{\prime}$-Cyclic Diguanylic Acid-Immunized 2-Year-Old C57BL/6J Mice}

CDG-induced memory $\mathrm{T}$ cell response, primarily Th1 and Th17, is impaired in aged mice (Figure 1D). Vaccine-induced Th1 responses are critical for the protection against intracellular pathogens, while Th17 responses, via enhancing neutrophil recruitment, are essential for clearing bacteria, e.g., Streptococcus pneumoniae infections. Next, we examined memory $\mathrm{T}$ cell responses in 2-year-old mice immunized with the moDCtargeting TNF fusion protein-adjuvanted $\mathrm{CDG} / \mathrm{NP}_{6} \mathrm{CGG}$ vaccine 60 days post the last immunization by ex vivo recall assay. We examined memory $\mathrm{T}$ cell production in the lung (mucosa) and spleen (systemic) in the immunized mice.

As expected, no Th1 (IFN- $\gamma$ ) or Th17 (IL-17a) was detected in the lungs of aged mice immunized with $\mathrm{CDG} / \mathrm{NP}_{6} \mathrm{CGG}$ only (Figures 5A,C). Similar to the 1-year-old mice, Th2 (IL-13), and IL-5 response was detected in the lungs from immunized aged mice (Figure 5B; Figure S6B). Remarkably, aged mice immunized with $\mathrm{CDG} / \mathrm{NP}_{6} \mathrm{CGG}$ plus moDC-targeting TNF fusion proteins elicited a significantly high level of Th1 $(p<0.0001)$, Th17 $(p<0.01)$ responses in the lungs (Figures 5A,C). Lung memory Th2 responses were not affected much by the addition of TNF-Fc fusion proteins (Figure 5B; Figure S6B). Similarly, spleen memory Th1 and Th17 responses were enhanced in $\mathrm{CDG} / \mathrm{NP}_{6} \mathrm{CGG} / \mathrm{TNF}-\mathrm{Fc}$ immunized 2-yearold mice (Figures 5D,F). Different from the lung, CDG/NP 6 CGG did not induce spleen memory Th2 responses in 2-year-old mice (Figure 5E; Figure S6A). However, the addition of TNFFc fusion proteins enhanced $\mathrm{CDG} / \mathrm{NP}_{6} \mathrm{CGG}$-induced spleen memory Th2 responses (Figure 5E; Figure S6A). The data, thus, indicated that solTNF-Fc (IgG2A) and tmTNF-Fc (IgG2A) restored CDG-induced memory $\mathrm{T}$ cell response in the systemic as well as mucosal compartments in the aged C57BL/6J mice.

\section{DISCUSSION}

In this report, we take a mechanism-guided rationally designed approach to improve vaccine efficacy in the middle-aged and aged mice. Our vaccine strategy is (i) to identify the in vivo mode of action of CDG adjuvant in the adult mice (20, 22); (ii) to define the defects in the aged mice that compromises CDG adjuvanticity in vivo; (iii) to design new biologics to circumvent the defective component in CDG mode of action and restore CDG adjuvanticity in the aged mice. Our new vaccine strategy focuses on moDC targeting and TNF induction because (i) CDG adjuvanticity is mediated by two DC subsets: $\mathrm{CDC} 2$ and moDCs (22); (ii) CDG-induced CDC2 production of TNF is critical for CDG adjuvanticity (19, 20, 22); (iii) aged mice had decreased cDC2 but increased moDCs; and (iv) CDG did not induce lung TNF in the aged mice. We designed the TNF-Fc (IgG2A) to targeted activating moDCs by TNF. Our strategy successfully restored CDG adjuvanticity in the middle-aged and aged mice.

Aging leads to a progressive decline of the innate and adaptive immune system that likely causes the reduced vaccine efficacy in the aged. Our vaccine strategy intends to adapt rather than change or reverse the immunosenescence in the aged. The current vaccine strategies to enhance vaccine responses in the elderly are empirical due to our limited understanding of immunosenescence (30). The success of our targeted vaccine strategy depends on the knowledge of CDG adjuvant mode of action in the adult and aged mice. This new strategy does not require a deep understanding of immunosenescence; thus, it is likely more practical for the development of vaccines for the aged.

It remains to be determined if our moDC-targeting TNF fusion proteins will enhance non-CDN vaccines in the aged. Most vaccines likely will have a mode of action different from CDNs. To adapt this targeted vaccine strategy requires efforts to understand the mode of action for each vaccine, which may be challenging. To solve this limitation, we are exploring if our moDC-targeting TNF fusion proteins can enhance the efficacy of non-CDN vaccines in the aged.

CDNs are excellent adjuvants eliciting not only long-lasting and potent antibody responses but also Th1, Th2, Th17, and antitumor CD8 T cell response. There were tremendous interests in translating CDNs into the clinic. For example, in 2015, Aduro Biotech and Novartis announced a \$250M-plus initiative to develop CDNs as cancer immunotherapies (31). Surprisingly, how aging affects CDN vaccine adjuvanticity was not well-addressed.

In early 2019, Darling et al. (32) showed that CDNs induced serum antibody production in 20-month-old female BALB/c mice. They did not examine memory $\mathrm{T}$ cell responses or distinguish high- and low-affinity antibody production (32). They immunized mice [subcutaneously (s.c.)] with $50 \mu \mathrm{g}$ OVA antigen and $20 \mu \mathrm{g}$ CDNs (32), a rather high dose of CDNs. In late December 2019, Vassilieva et al. (33) showed that $2^{\prime} 3^{\prime}$-cGAMP (5 


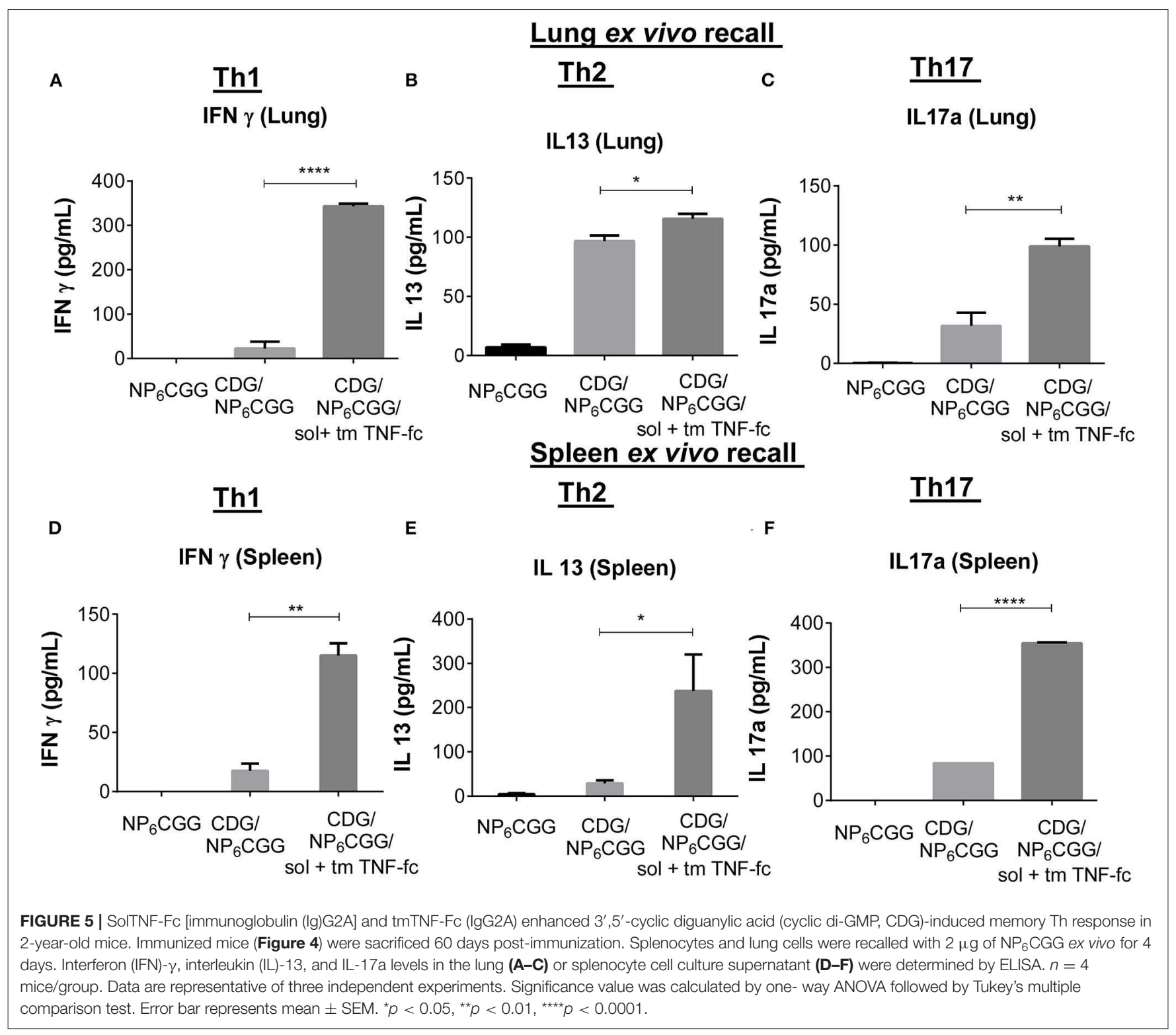

$\mu \mathrm{g}$ ) adjuvanted with $1 \mu \mathrm{g}$ of hemagglutinin (HA) [intradermally (i.d.)] did not induce antibodies or protective immunity in the 19-month-old female BALB/c mice. And 100\% aged mice immunized (i.d.) with $2^{\prime} 3^{\prime}$-cGAMP/HA died subsequently from influenza infection (33). In comparison, $75 \%$ of aged mice immunized with Quil-A, a saponin adjuvant, with HA antigen immunization (i.d.) survived from influenza infection (33). Our observations here are in line with this latest result. We found that the antigen-specific high-affinity antibody production and memory Th1, Th17 responses were markedly reduced in 2-yearold mice. Our results further showed that even 1-year-old mice were defective in CDG-induced Th1 and Th17 responses.

Vaccination offers the most efficient and cost-effective method of preventing infectious diseases. However, vaccines are less effective in the elderly. For instance, the influenza vaccine has an efficacy between 70 and $90 \%$ in children and adults but dropping to $30-50 \%$ for those over 65 years of age $(4,34)$. Similarly, responses to pneumococcal polysaccharide and hepatitis $\mathrm{B}$ vaccines are compromised by the old age (35). In addition, $\sim 83 \%$ of pneumonia deaths in the US occurred in the elderly $(36,37)$. Last, people 45 and older (middle-aged and aged) account for $\sim 97 \%$ of COVID-19 deaths (1). Methods to improve vaccine protection in the elderly are highly desirable. We used the model antigen $\mathrm{NP}_{6} \mathrm{CGG}$ to reveal a defect of high-affinity antibody and Th1/17 induction in the middle-aged and aged mice. We observed the aged-related defect using H1N1-NP and PspA antigens. TNF-Fc fusion protein enhanced the duration (120 days post-immunization) and the magnitude of CDG/PspA antibody production in 1-year-old mice. CDN-adjuvanted protein subunit vaccines protected adult mice from respiratory infections such as influenza $(38,39)$, bacterial pneumonia (40), Mycobacterium tuberculosis (41), and anthrax (42). CDNs were also therapeutic 
for cancer in adult mice $(13,14)$. Future studies are needed to determine if the TNF-Fc fusion proteins can improve protection in $\mathrm{CDN}$-adjuvanted vaccines for infectious diseases and cancers in the elderly.

As a vaccine specific to the elderly, safety is paramount. Intranasally administered CDG ( $5 \mu \mathrm{g} /$ mouse) does not cause acute toxicity in mice $(20,43,44)$ and is proven safe in various animal models $(38,40,44-47)$. Clinical trials on CDNs (ClinicalTrials.gov NCT02675439, NCT03010176, NCT03172936, NCT03937141, and NCT0414414) have established an excellent safety file in humans, including the elderly. The human body makes TNF. Low-dose (ng) targeted delivered TNF biologics are likely safe in the elderly as well. Nevertheless, a future study is needed to establish a safety profile for the CDG/TNF biologics vaccines for the elderly.

Last, the moDC-targeting TNF fusion proteins applied here did not have adjuvant activity when administered in the absence of CDG. Furthermore, TNF when used as a mucosal adjuvant mainly induces Th2 responses (29). Here, moDC-targeting TNF biologics enhanced memory Th1 and Th17-immunity of the CDG. We propose that TNF fusion proteins enhanced CDG adjuvanticity rather than acted as a separate adjuvant to replace CDG in aged mice. In all, we showed that aging negatively influences CDG adjuvanticity, especially CDG-induced memory Th1 and Th17 responses. A new moDC-targeting strategy can restore CDG adjuvanticity in middle-aged and aged mice.

\section{REFERENCES}

1. Dowd JB, Andriano L, Brazel DM, Rotondi V, Block P, Ding X, et al. Demographic science aids in understanding the spread and fatality rates of COVID-19. Proc Natl Acad Sci USA. (2020) 117:96968. doi: $10.1101 / 2020.03 .15 .20036293$

2. Alpert A, Pickman Y, Leipold M, Rosenberg-Hasson Y, Ji X, Gaujoux $\mathrm{R}$, et al. A clinically meaningful metric of immune age derived from high-dimensional longitudinal monitoring. Nat Med. (2019) 25:48795. doi: 10.1038/s41591-019-0381-y

3. Poland GA, Ovsyannikova IG, Kennedy RB. Personalized vaccinology: a review. Vaccine. (2018) 36:5350-7. doi: 10.1016/j.vaccine.2017.07.062

4. Osterholm MT, Kelley NS, Sommer A, Belongia EA. Efficacy and effectiveness of influenza vaccines: a systematic review and meta-analysis. Lancet Infect Dis. (2012) 12:36-44. doi: 10.1016/S1473-3099(11)70295-X

5. Wiener JM, Tilly J. Population ageing in the United States of America: implications for public programmes. Int J Epidemiol. (2002) 31:77681. doi: $10.1093 / \mathrm{ije} / 31.4 .776$

6. Sasaki S, Sullivan M, Narvaez CF, Holmes TH, Furman D, Zheng NY, et al. Limited efficacy of inactivated influenza vaccine in elderly individuals is associated with decreased production of vaccine-specific antibodies. J Clin Invest. (2011) 121:3109-19. doi: 10.1172/JCI57834

7. Stiasny K, Aberle JH, Keller M, Grubeck-Loebenstein B, Heinz FX. Age affects quantity but not quality of antibody responses after vaccination with an inactivated flavivirus vaccine against tick-borne encephalitis. PLoS ONE. (2012) 7:e34145. doi: 10.1371/journal.pone.0034145

8. van Werkhoven CH, Huijts SM, Bolkenbaas M, Grobbee DE, Bonten MJ. The impact of age on the efficacy of 13-valent pneumococcal conjugate vaccine in elderly. Clin Infect Dis. (2015) 61:1835-8. doi: 10.1093/cid/civ686

\section{DATA AVAILABILITY STATEMENT}

All datasets presented in this study are included in the article/Supplementary Material.

\section{ETHICS STATEMENT}

The animal study was reviewed and approved by Institutional Animal Care and Use Committee, University of Florida.

\section{AUTHOR CONTRIBUTIONS}

SM and LJ conceived the research. LJ designed the experiments, wrote the manuscript, and supervised the research. HG, SM, DK, and LJ performed experiments and analyzed the data. HG drafted the manuscript. All authors contributed to the article and approved the submitted version.

\section{FUNDING}

This work was supported by NIH grants AI110606, AI125999, and AI132865 (to LJ).

\section{SUPPLEMENTARY MATERIAL}

The Supplementary Material for this article can be found online at: https://www.frontiersin.org/articles/10.3389/fimmu. 2020.01674/full\#supplementary-material

9. Bonten MJ, Huijts SM, Bolkenbaas M, Webber C, Patterson S, Gault S, et al. Polysaccharide conjugate vaccine against pneumococcal pneumonia in adults. N Engl J Med. (2015) 372:1114-25. doi: 10.1056/NEJMoa1408544

10. Oviedo-Orta E, Li CK, Rappuoli R. Perspectives on vaccine development for the elderly. Curr Opin Immunol. (2013) 25:529-34. doi: 10.1016/j.coi.2013.07.008

11. Lefebvre JS, Haynes L. Vaccine strategies to enhance immune responses in the aged. Curr Opin Immunol. (2013) 25:523-8. doi: 10.1016/j.coi.2013.05.014

12. Boraschi D, Italiani $P$. Immunosenescence and vaccine failure in the elderly: strategies for improving response. Immunol Lett. (2014) 162:34653. doi: 10.1016/j.imlet.2014.06.006

13. Corrales L, Glickman LH, McWhirter SM, Kanne DB, Sivick KE, Katibah GE, et al. Direct activation of sting in the tumor microenvironment leads to potent and systemic tumor regression and immunity. Cell Rep. (2015) 11:1018-30. doi: 10.1016/j.celrep.2015.04.031

14. Fu J, Kanne DB, Leong M, Glickman LH, McWhirter SM, Lemmens $\mathrm{E}$, et al. STING agonist formulated cancer vaccines can cure established tumors resistant to PD-1 blockade. Sci Transl Med. (2015) 7:283ra52. doi: 10.1126/scitranslmed.aaa4306

15. Dubensky TW Jr, Kanne DB, Leong ML. Rationale, progress and development of vaccines utilizing STING-activating cyclic dinucleotide adjuvants. Ther $A d v$ Vaccines. (2013) 1:131-43. doi: 10.1177/2051013613501988

16. Chen W, Kuolee R, Yan H. The potential of $3^{\prime}, 5^{\prime}$-cyclic diguanylic acid (c-di-GMP) as an effective vaccine adjuvant. Vaccine. (2010) 28:30805. doi: 10.1016/j.vaccine.2010.02.081

17. Ebensen T, Debarry J, Pedersen GK, Blazejewska P, Weissmann S, Schulze $\mathrm{K}$, et al. Mucosal administration of cycle-di-nucleotide-adjuvanted virosomes efficiently induces protection against influenza H5N1 in Mice. Front Immunol. (2017) 8:1223. doi: 10.3389/fimmu.2017.01223 
18. Wang Z, Celis E. STING activator c-di-GMP enhances the anti-tumor effects of peptide vaccines in melanoma-bearing mice. Cancer Immunol Immunother. (2015) 64:1057-66. doi: 10.1007/s00262-015-1713-5

19. Hanson MC, Crespo MP, Abraham W, Moynihan KD, Szeto GL, Chen SH, et al. Nanoparticulate STING agonists are potent lymph node-targeted vaccine adjuvants. J Clin Invest. (2015) 125:2532-46. doi: 10.1172/JCI79915

20. Blaauboer SM, Gabrielle VD, Jin L. MPYS/STING-mediated TNF- $\alpha$, not type I IFN, is essential for the mucosal adjuvant activity of $\left(3^{\prime}-5^{\prime}\right)$ cyclic-di-guanosine-monophosphate in vivo. J Immunol. (2014) 192:492502. doi: 10.4049/jimmunol.1301812

21. Blaauboer SM, Mansouri S, Tucker HR, Wang HL, Gabrielle VD, Jin L. The mucosal adjuvant cyclic di-GMP enhances antigen uptake and selectively activates pinocytosis-efficient cells in vivo. Elife. (2015) 4:e06670. doi: 10.7554/eLife.06670

22. Mansouri S, Patel S, Katikaneni DS, Blaauboer SM, Wang W, Schattgen S, et al. Immature lung TNFR2(-) conventional DC 2 subpopulation activates moDCs to promote cyclic di-GMP mucosal adjuvant responses in vivo. Mucosal Immunol. (2019) 12:277-89. doi: 10.1038/s41385-018-0098-0

23. Richardson S, Hirsch JS, Narasimhan M, Crawford JM, McGinn T, Davidson $\mathrm{KW}$, et al. Presenting characteristics, comorbidities, and outcomes among 5700 patients hospitalized with COVID-19 in the New York City area. JAMA. (2020) 323:2052-9. doi: 10.1001/jama.2020.6775

24. Tsai CJ, Griffin MR, Nuorti JP, Grijalva CG. Changing epidemiology of pneumococcal meningitis after the introduction of pneumococcal conjugate vaccine in the United States. Clin Infect Dis. (2008) 46:166472. doi: $10.1086 / 587897$

25. Loetscher H, Stueber D, Banner D, Mackay F, Lesslauer W. Human tumor necrosis factor alpha (TNF alpha) mutants with exclusive specificity for the 55-kDa or 75-kDa TNF receptors. J Biol Chem. (1993) 268:26350-7.

26. Langlet C, Tamoutounour S, Henri S, Luche H, Ardouin L, Gregoire C, et al. CD64 expression distinguishes monocyte-derived and conventional dendritic cells and reveals their distinct role during intramuscular immunization. $J$ Immunol. (2012) 188:1751-60. doi: 10.4049/jimmunol.1102744

27. Guilliams M, Bruhns P, Saeys Y, Hammad H, Lambrecht BN. The function of Fc $\gamma$ receptors in dendritic cells and macrophages. Nat Rev Immunol. (2014) 14:94-108. doi: 10.1038/nri3582

28. Mansouri S, Katikaneni D, Gogoi H, Jin L. Mucosal vaccine adjuvant cyclic di-GMP differentiates lung moDCs into Bcl6+ and Bcl6- mature moDCs to induce lung memory CD4+ TH cells and lung TFH cells respectively. bioRxiv. (2020) 2020:135244. doi: 10.1101/2020.06.04.135244

29. Kayamuro H, Abe Y, Yoshioka Y, Katayama K, Nomura T, Yoshida $\mathrm{T}$, et al. The use of a mutant TNF- $\alpha$ as a vaccine adjuvant for the induction of mucosal immune responses. Biomaterials. (2009) 30:586976. doi: 10.1016/j.biomaterials.2009.07.009

30. Ciabattini A, Nardini C, Santoro F, Garagnani P, Franceschi C, Medaglini D. Vaccination in the elderly: the challenge of immune changes with aging. Semin Immunol. (2018) 40:83-94. doi: 10.1016/j.smim.2018.10.010

31. Patel S, Jin L. TMEM173 variants and potential importance to human biology and disease. Genes Immun. (2019) 20:82-9. doi: 10.1038/s41435-0180029-9

32. Darling RJ, Senapati S, Kelly SM, Kohut ML, Narasimhan B, Wannemuehler MJ. STING pathway stimulation results in a differentially activated innate immune phenotype associated with low nitric oxide and enhanced antibody titers in young and aged mice. Vaccine. (2019) 37:272130. doi: 10.1016/j.vaccine.2019.04.004

33. Vassilieva EV, Taylor DW, Compans RW. Combination of STING pathway agonist with saponin is an effective adjuvant in immunosenescent Mice. Front Immunol. (2019) 10:3006. doi: 10.3389/fimmu.2019.03006

34. Jefferson T, Rivetti D, Rivetti A, Rudin M, Di Pietrantonj C, Demicheli V. Efficacy and effectiveness of influenza vaccines in elderly people: a systematic review. Lancet. (2005) 366:1165-74. doi: 10.1016/S0140-6736(05)67339-4

35. Siegrist CA, Aspinall R. B-cell responses to vaccination at the extremes of age. Nat Rev Immunol. (2009) 9:185-94. doi: 10.1038/nri2508

36. van Buynder P, Booy R. Pneumococcal vaccination in older persons: where are we today? Pneumonia (Nathan). (2018) 10:1. doi: 10.1186/s41479-017-0045-y

37. Boe DM, Boule LA, Kovacs EJ. Innate immune responses in the ageing lung. Clin Exp Immunol. (2017) 187:16-25. doi: 10.1111/cei.12881

38. Madhun AS, Haaheim LR, Nostbakken JK, Ebensen T, Chichester J, Yusibov V, et al. Intranasal c-di-GMP-adjuvanted plant-derived H5 influenza vaccine induces multifunctional Th1 CD4+ cells and strong mucosal and systemic antibody responses in mice. Vaccine. (2011) 29:497382. doi: 10.1016/j.vaccine.2011.04.094

39. Wang J, Li P, Yu Y, Fu Y, Jiang H, Lu M, et al. Pulmonary surfactantbiomimetic nanoparticles potentiate heterosubtypic influenza immunity. Science. (2020) 367:eaau0810. doi: 10.1126/science.aau0810

40. Ogunniyi AD, Paton JC, Kirby AC, McCullers JA, Cook J, Hyodo $\mathrm{M}$, et al. c-di-GMP is an effective immunomodulator and vaccine adjuvant against pneumococcal infection. Vaccine. (2008) 26:4676-85. doi: 10.1016/j.vaccine.2008.06.099

41. Van Dis E, Sogi KM, Rae CS, Sivick KE, Surh NH, Leong ML, et al. STING-activating adjuvants elicit a Th17 immune response and protect against mycobacterium tuberculosis infection. Cell Rep. (2018) 23:143547. doi: 10.1016/j.celrep.2018.04.003

42. Martin TL, Jee J, Kim E, Steiner HE, Cormet-Boyaka E, Boyaka PN. Sublingual targeting of STING with $3^{\prime} 3^{\prime}$-cGAMP promotes systemic and mucosal immunity against anthrax toxins. Vaccine. (2017) 35:25119. doi: 10.1016/j.vaccine.2017.02.064

43. Libanova R, Ebensen T, Schulze K, Bruhn D, Norder M, Yevsa T, et al. The member of the cyclic di-nucleotide family bis- $\left(3^{\prime}, 5^{\prime}\right)$-cyclic dimeric inosine monophosphate exerts potent activity as mucosal adjuvant. Vaccine. (2009) 28:2249-58. doi: 10.1016/j.vaccine.2009.12.045

44. Yan H, KuoLee R, Tram K, Qiu H, Zhang J, Patel GB, et al. 3',5'-Cyclic diguanylic acid elicits mucosal immunity against bacterial infection. Biochem Biophys Res Commun. (2009) 387:581-4. doi: 10.1016/j.bbrc.2009.07.061

45. Zhao L, KuoLee R, Harris G, Tram K, Yan H, Chen W. c-di-GMP protects against intranasal Acinetobacter baumannii infection in mice by chemokine induction and enhanced neutrophil recruitment. Int Immunopharmacol. (2010) 11:1378-83. doi: 10.1016/j.intimp.2011.03.024

46. Hu DL, Narita K, Hyodo M, Hayakawa Y, Nakane A, Karaolis DK. c-diGMP as a vaccine adjuvant enhances protection against systemic methicillinresistant Staphylococcus aureus (MRSA) infection. Vaccine. (2009) 27:486773. doi: 10.1016/j.vaccine.2009.04.053

47. Karaolis DK, Newstead MW, Zeng X, Hyodo M, Hayakawa Y, Bhan U, et al. Cyclic di-GMP stimulates protective innate immunity in bacterial pneumonia. Infect Immun. (2007) 75:4942-50. doi: 10.1128/IAI.01762-06

Conflict of Interest: LJ and SM are co-Inventors on a patent (PCT/US19/53548) on the moDCs-targeting TNF fusion proteins.

The remaining authors declare that the research was conducted in the absence of any commercial or financial relationships that could be construed as a potential conflict of interest.

Copyright (C) 2020 Gogoi, Mansouri, Katikaneni and Jin. This is an open-access article distributed under the terms of the Creative Commons Attribution License (CC BY). The use, distribution or reproduction in other forums is permitted, provided the original author(s) and the copyright owner(s) are credited and that the original publication in this journal is cited, in accordance with accepted academic practice. No use, distribution or reproduction is permitted which does not comply with these terms. 